\title{
Real-time Measurements of the Particle Geometric Surface Area by the Weighted- sum Method on a University Campus
}

\author{
Leo N.Y. Cao ${ }^{*}$, David Y.H. Pui ${ }^{2}$ \\ ${ }^{1}$ Division of Complex Drug Analysis, US Food and Drug Administration, St. Louis, MO 63110, USA \\ ${ }^{2}$ Particle Technology Laboratory, University of Minnesota, Minneapolis, MN 55455, USA
}

\begin{abstract}
This study conducted field measurements of the particle geometric surface area (GSA) and number concentrations on a university campus via two real-time approaches: applying the weighted-sum (WS) method and using a Scanning Mobility Particle Sizer (SMPS). The measurements were conducted on 4 subjects: laser printing, 3D printing, machining (waterjet cutting, sanding, and welding), and environmental aerosols. The highest emissions were found with 3D printing and welding; these concentrations were measured in the printer's enclosure and when the local exhaust ventilation was on, respectively. In general, the two methods agreed well with each other, with an overall Pearson correlation coefficient of 0.85 , although the concentrations constantly fluctuated over a wide range, from 20 to $4 \times 10^{4} \mu^{2} \mathrm{~cm}^{-3}$. Since the GSA concentrations reported in this study are the first measurements for some scenarios, our results can serve as a reference for further research as well as for individuals in the vicinity of these emissions.
\end{abstract}

Keywords: Geometric surface area; Real-time; Weighted sum; Occupational exposure; 3D printing emission.

\section{INTRODUCTION}

Since recent toxicological studies showed that the surface area of nanoparticles has better correlation with the adverse health effect than their mass (Oberdörster, 2000; LeBouf et al., 2011; Schmid and Stoeger, 2016), more surface area measurements were conducted and discussion was aroused about some kind of surface area should be introduced as an additional metric (Ramachandran et al., 2005; Baldauf et al., 2016) to characterize the nanoparticle exposure and health effects. More specifically, Schmid and Steoger (2016) concluded that for nonporous spherical particles the geometric surface area (GSA) can be "used as biologically most relevant dose metric," where the GSA is defined as the envelope surface area of particles. The well-known Scanning Mobility Particle Sizer (SMPS) offers quasi-real-time size-resolved particle size distribution in minutes. Mobility-based surface area can be calculated based on the integrated distribution. Note that for spherical particles, the surface area is equal to the GSA. There are other techniques to measure aerosol parameters close to the GSA in different time resolutions. The offline BET method (Brunauer et al., 1938) measures the accumulative specific surface area, used as a metric in many toxicology studies (Bau et al., 2011; LeBouf et al., 2011). Schmid and

\footnotetext{
* Corresponding author.

E-mail address: leo.n.y.cao@gmail.com
}

Steoger (2016) pointed out that for porous and arbitrarily shaped particles (except fibers), the BET surface area is expected to be the biologically more effective dose metric than the GSA. However, in contrast to the GSA, there is currently no real-time BET method due to its high detection limit that leads to tremendous amounts of sampling time when the majority of the aerosol are submicron particles. Thus, for nonporous spherical particles, the GSA can be used as biologically most relevant dose metric. Electron microscopy, another offline method, provides visualization and quantitative analysis of the 2D projection of sampled particles. Bau et al. (2010) had developed a TEM-based method as an alternative to the BET method. However, researchers are still struggling to reduce the time for routine analysis of TEM images and the uncertainty caused by human subjectivity and measurement reproducibility (Bourrous et al., 2018). The epiphaniometer (EPI; Gäggeler et al., 1989) is the first device designed specifically to monitor the active surface area of aerosols of any kind via the calculation of the attachment rate of labeling material to the aerosol. Gini $e t$ al. (2013) later developed a six-stage cascade epiphaniometer (CEPI) to measure the distribution of aerosol active surface area in real time. However, the inclusion of a radioactive source $(227 \mathrm{Ac})$ as the labeling material makes the EPI inappropriate for routine field use.

Diffusion chargers (DC) (e.g., the Electrical Aerosol Detector [EAD] Model 3070A; TSI Inc.) can also measure the active surface area in real time. DC shares a common operation principle with the EPI. However, the use of the 
electrical ions as the labeling material makes it very popular in field measurements. Due to the need of in situ exposure measurements, many DCs were modified (Fissan et al., 2007; Marra et al., 2010; Fierz et al., 2011, 2013) and calibrated based on ICRP lung deposition curve (ICRP, 1994) in order to measure the particle lung-deposited surface area (LDSA) concentration, which is expected to be great in aerosol exposure measurement. Because of the portability and real-time capability, many environment measurements for exposure monitoring were using DC (Mokhtar et al., 2013; Todea et al., 2015; Geiss et al., 2016). Iavicoli (2018) applied several DC to conduct personal exposure sampling, which will be very difficult for other bulkier benchtop instruments. Kuuluvainen et al. (2018) even installed DC into a multirotor drone to study the vertical profile of the aerosol LDSA concentration of a street canyon.

However, the GSA on which many toxicological data are based is still more relevant to toxicity than active or lungdeposited surface area. Furthermore, the active surface area is only a portion of the GSA by the definition and measurements (Pandis et al., 1991; Jung and Kittelson, 2005). Ku (2010) found that the deviation of the DC-based surface area from the GSA was up to $94 \%$ from 100 to $900 \mathrm{~nm}$. Some progress was made on the manipulation of the DC response (Fierz et al., 2008; Li et al., 2009; Marra et al., 2010; Cao et al., 2015; Fierz et al., 2011) towards the GSA measurements (Wei, 2007; Cao et al., 2017). Based on the previous studies, Cao and Pui (2018) developed a weighted-sum (WS) method coupled with DC with a potential resolution of $1 \mathrm{~s}$, where the instrument response correlates well with the GSA of spherical particles with a much wider working range compared with previous studies. Based on the WS method, we developed more methods and prototypes with 1-s resolution to measure the GSA and other parameters for particles in different shapes (Su et al., 2019a, b).

Since the method has only been established recently, more field measurements are needed to explore the possibility of the WS method on more scenarios. Note that although many studies on field measurements were using SMPS that can offer the GSA concentration, the data were not always expressed in the form of the GSA since they were using SMPS as a comparison to other surface areas (e.g., LDSA) other than the GSA. Thus, a GSA concentration reference that individuals and researchers can refer to is missing. The current study applies the WS method (Cao and Pui, 2018) along with SMPS and conducts several field measurements where emission concerns were raised on a university campus. The events of measurements include laser printing, 3D printing, machining (waterjet cutting, sanding, and welding), and outdoor air quality. The emission profile could add to the database of GSA measurements and serve as a reference for future studies.

\section{METHODOLOGY}

The current investigation involved field samplings of aerosol geometric surface area concentrations on the University of Minnesota campus. The data can help explore the possibility of the weighted-sum method (Cao and Pui,
2018) for various environments and provide a reference on environmental GSA concentrations.

The WS method and SMPS, which are both targeted at submicron particles, were sampling by parallel. SMPS consists of a ${ }^{210} \mathrm{Po}$ neutralizer (TSI Inc.), a Differential Mobility Analyzer (DMA; Model 3081; TSI Inc.), and a condensation particle counter (CPC; Model 3776; TSI Inc.) and delivers the aerosol size distribution (up to 64 particle size bins) in minutes. Both particle number (PN) and GSA concentrations/distributions can be delivered by SMPS. Note that all the PN concentrations mentioned in this study were measured by SMPS. We used $0.3 \mathrm{~L} \mathrm{~min}^{-1}$ as the aerosol flow rate (CPC) and $3 \mathrm{~L} \mathrm{~min}^{-1}$ as the sheath flow rate of DMA. One cycle of SMPS scan is $60 \mathrm{~s}, 50 \mathrm{~s}$ of sampling and $10 \mathrm{~s}$ of retrace.

The WS method was designed to monitor aerosol GSA concentrations in real time by correlating the instrument response with the integral of aerosol GSA concentrations. The method applies a novel mathematic algorithm on top of the unipolar diffusion charging, where two independent signals within several seconds are combined in a weightedsum fashion to correlate with aerosol GSA concentrations. The WS method used the Nanoparticle Surface Area Monitor (NSAM; Model 3550, discontinued as of March $31^{\text {st }}$, 2018; TSI Inc., Shoreview, MN; Fissan et al., 2007) as the basic instrument. The aerosol first got charged by the positive ions, excess ions were then removed in the trap (an electrostatic precipitator), and finally, the electrical current produced by the charges on the particles was measured by the electrometer (Fig. 1). Several researchers found that by altering the voltage $(V)$ of the trap, the instrument sensitivity (the ratio of the total current to the total PN concentration) for monodisperse, spherical particles can be manipulated and became proportional to the GSA of a single particle (Wei, 2007; Li et al., 2009), which is the sufficient condition for a direct reading monitor to measure the integrated GSA for the aerosol (Fissan et al., 2007; Wei, 2007). However, the working range is limited, e.g., 20-100 nm in Wei (2007). Cao and Pui (2018) found that when combining two independent sensitivities under two carefully chosen voltages for the same aerosol in a weighted-sum fashion (Eq. (1)), the proportionality between the GSA and instrument response can be achieved (Eq. (2)) in a much wider range, 20-300 nm:

$S_{W S}\left(d, V_{1}, V_{2, c}\right)=S\left(d, V_{1}\right)+c S\left(d, V_{2}\right)$

where $S\left(d, V_{1}\right)$ is the sensitivity at $20 \mathrm{~V}, S\left(d, V_{2}\right)$ is the one at $2400 \mathrm{~V}$, and $c$ is the weighting factor (a constant) that can be determined by the instrument calibration, and

$k S_{W S}\left(d, V_{1}, V_{2, c}\right)=\pi d^{2}$

where $k$ is a constant that can be easily determined when $S_{W S}$ is known.

As described in Eqs. (1) and (2), the sensitivity was rigorously tested with monodisperse, nearly spherical particles ( $\mathrm{KCl}$ in Cao and Pui, 2018; PSL and gold in Cao et al., 2017) size by size from $20 \mathrm{~nm}$ up to $487 \mathrm{~nm}$ during the calibration.

To obtain two independent instrument responses (electrical 


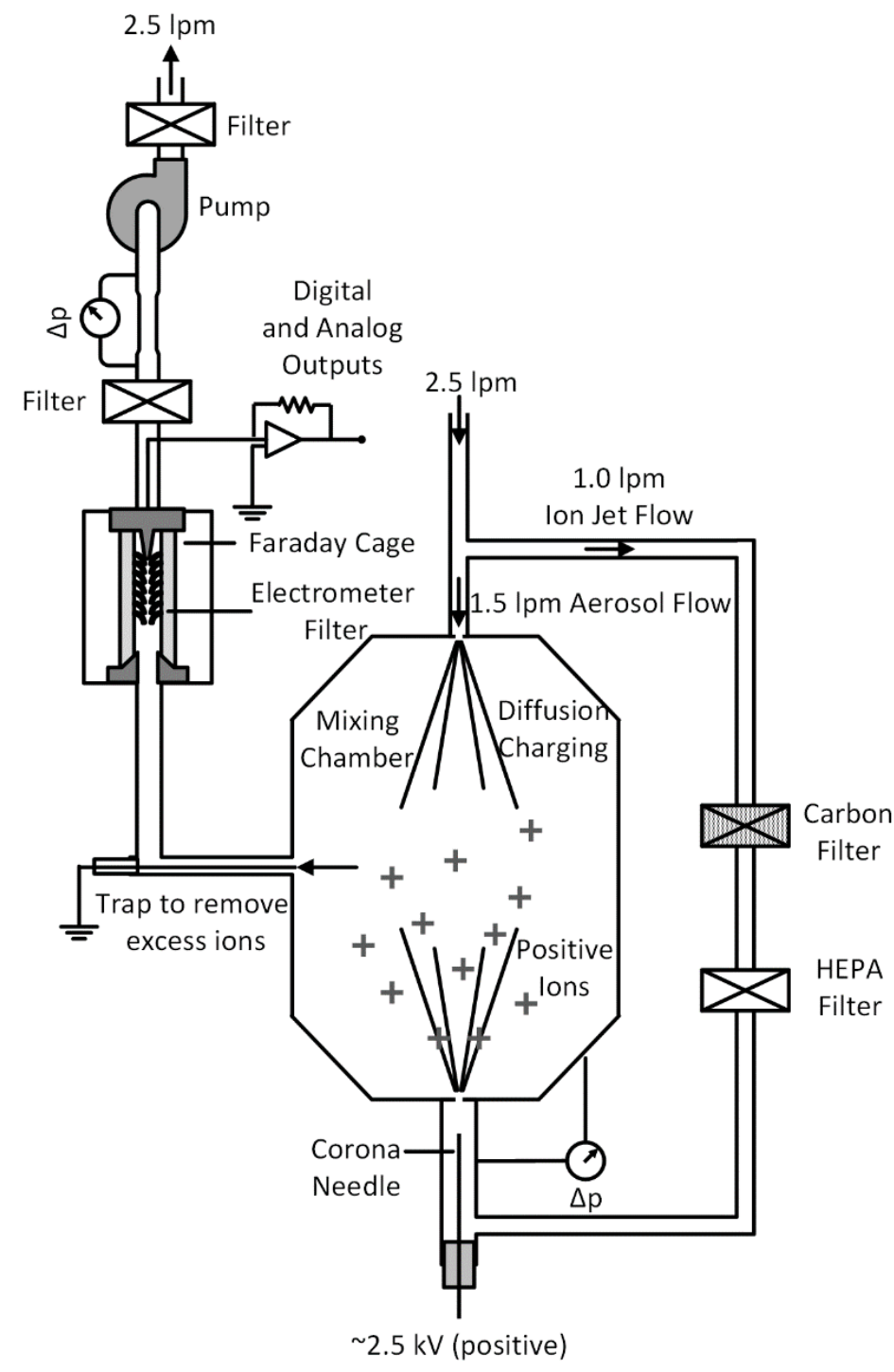

Fig. 1. The schematic diagram of the Nanoparticle Surface Area Monitor (NSAM).

currents) for the combination, the voltages of the trap were switching back and forth in a stepwise pattern between $20 \mathrm{~V}$ and $2400 \mathrm{~V}$, which is controlled by Labview 2014 (National Instruments). In every $60 \mathrm{~s}$, the voltage stayed at $20 \mathrm{~V}$ for the first $30 \mathrm{~s}$ and $2400 \mathrm{~V}$ for the second $30 \mathrm{~s}$. When switching the voltage from $20 \mathrm{~V}$ to $2400 \mathrm{~V}$, we observed a 3-s delay for the current; when switching from $2400 \mathrm{~V}$ to $20 \mathrm{~V}$, the delay time was about $25 \mathrm{~s}$. Thus, for usable data, we only took data from time $t-5$ to $t$ and $t+5$ to $t+10$ if we define the time of switching from $20 \mathrm{~V}$ to $2400 \mathrm{~V}$ as time $t$. We averaged 6 data points for $20 \mathrm{~V}$ from time $t-5$ to $t$ and 6 data points for $2400 \mathrm{~V}$ from $t+5$ to $t+10$ and obtained the standard deviations $\left(\sigma_{20}\right.$ and $\left.\sigma_{2400}\right)$. Two averaged values were combined according to Eq. (6) in Cao and Pui (2018) and the standard deviation for the combined data is $\sqrt{\sigma_{20}^{2}+c^{2} \sigma_{2400}^{2}}$ according to the propagation of uncertainty rules. Note that we assumed the aerosol was stable within $16 \mathrm{~s}$. If the averaged value is not needed, the assumed stable time is only $6 \mathrm{~s}$.
Although the algorithm itself has no limitation on the time resolution, the hardware was not optimal and the potential of the algorithm was not maximized in the current measurements. Fortunately, in our recent studies, Su et al. (2019a) applied two parallel DC for the algorithm, one with a high voltage and another with a low voltage, and maximized the resolution to $1 \mathrm{~s}$. Furthermore, Su et al. (2019b) had extended the WS method to both the GSA and mass measurement for labgenerated nano-agglomerates and -aggregates.

The field measurements include several representative indoor/outdoor emission events and the detail was listed as follows:

\section{Laser Printing in the Student Computer Lab}

The particle emission of a laser printer was measured in the student computer lab on an ordinary Tuesday afternoon, March $14^{\text {th }}$, 2017. Fig. 2 shows the working principle of laser printing. Laser printing is an electrostatic digital printing process. First, the photoreceptor drum is positively charged by the corona wire. As the drum revolves, a laser beam 


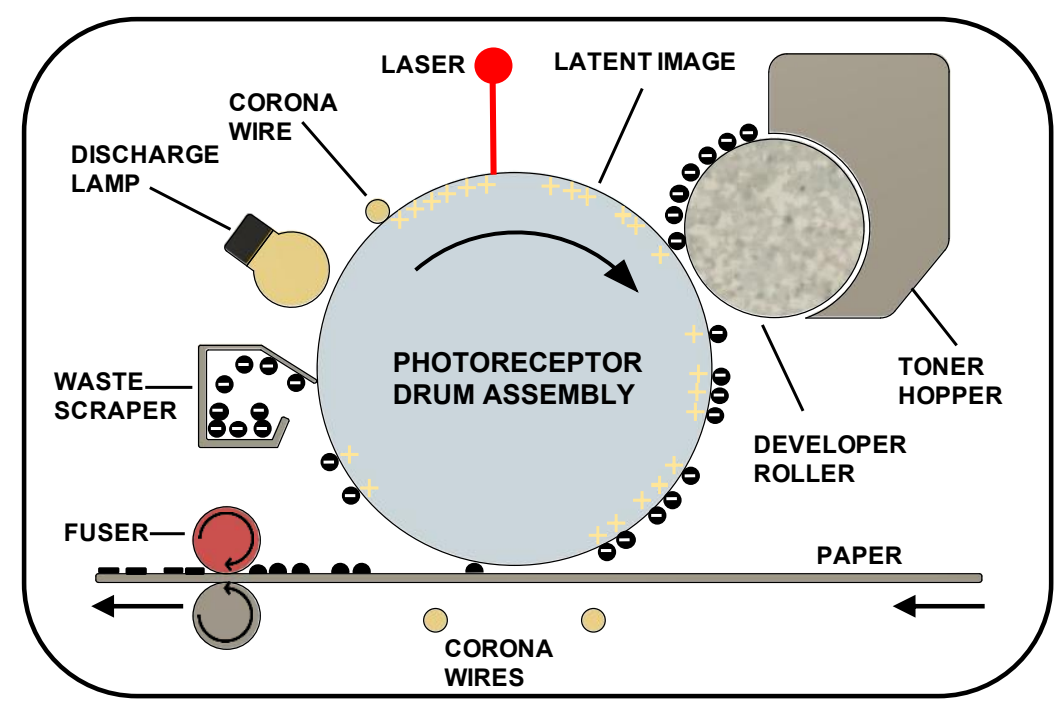

Fig. 2. The working principle of laser printing.

shines across the surface to discharge certain points. The remaining positively charged area of the drum is coated with the negatively charged toner and rolls over a sheet of paper. Finally, the paper with the attached toner passes through the fuser, a pair of heated rollers $\left(137-205^{\circ} \mathrm{C}\right.$ in $\mathrm{He}$ et al., 2010). As the paper passes through the fuser, the loose toner powder and the paper melt together and the paper is printed. Morawska et al. (2009) indicated that the fusing could be the major source for particle emission.

The printer, a color laser printer (HP LaserJet M651), was located against the wall of the room near the room entrance. The room is a regular computer lab containing a total of 30 computers on the tables. The aerosol instruments located $10 \mathrm{~cm}$ away from the outlet of the exhaust fan of the printer to make sure the emission is high enough and distinguishable from the background. During the 1-h continuous sampling, 4 print jobs happened and were fully covered by the sampling. The print jobs include the printing of black plain texts ( $\sim 5 \%$ toner coverage), text and pictures in color $(\sim 10 \%$ toner coverage), pictures in color $(\sim 40 \%$ toner coverage), and pictures in red ( $20 \%$ toner coverage) chronologically. More detail of the prints can be found in Table 1.

\section{D Printing in the Student Workshop}

The 3D printer we aim to measure, Dimension 1200es SST from Stratasys Inc., is a fused deposition modeling (FDM) printer with dual extruders. The printer comes with an enclosure and an internal air-circulation system (4 chamber fans, $1104 \mathrm{~L} \mathrm{~min}^{-1}$ ) with HEPA filters, which intends to maintain a uniform temperature to reduce filament warping. The measurement was carried out in a room that was $4.3 \mathrm{~m}$ long and $3.7 \mathrm{~m}$ wide (Fig. 3). The max airflow for the room is approximately $28,317 \mathrm{~L} \mathrm{~min}^{-1}$ with 6 air changes per h. The Dimension 3D printer was against the wall and the aerosol instruments were next to the $3 \mathrm{D}$ printer in the middle of the room. Two other 3D printers, both Fusion 3 F410, were in the room as well. The one next to Dimension was out of service and the one in the upper left corner was printing during the whole field measurement.
For the 3-h continuous sampling, two identical wrenches were printed with dual extruders during the measurement, one loaded with acrylonitrile butadiene styrene (ABS) filament for the main-body print and another with support material SR 20, which is mainly acrylic copolymer. A simple schematic diagram of the working principle of 3D printing is shown in Fig. 4. At the beginning of the printing, the enclosure and materials in the extruder nozzle were preheated to approximately $75^{\circ} \mathrm{C}$ and $300^{\circ} \mathrm{C}$, respectively. The materials were then extruded layer by layer on the building plate, where the two extruders switched back and forth depending on how the 3D model was sliced, namely, translated into individual layers. When the print was finished, the support material was removed manually from the main body. The concentrations were measured outside and inside the enclosure for the $1^{\text {st }}$ and the $2^{\text {nd }}$ prints, respectively. The sampling inlet for the $1^{\text {st }}$ print located about $20 \mathrm{~cm}$ away from the enclosure door, while the one for the $2^{\text {nd }}$ print was inside the enclosure close to the door.

\section{Machining in the Machine Shop}

The measurement was planned in the machine shop in the Mechanical Engineering Building from 11:00 to 16:00. Multiple events were measured including waterjet cutting (Mach 2 2020c; Flow International Corporation), belt grinding (Model 760; Burr King), and welding. Waterjet is capable of cutting a wide variety of materials using a very high-pressure jet of water, or a mixture of water and an abrasive substance. Here, we used the high-performance garnet abrasives (80 HPA; Barton International) for cutting a metal sheet. Belt grinding is an abrasive machining process, which runs an abrasive-coated belt over the surface of the part to be processed. A metal part was ground during the measurement. Welding is a process that joins materials, usually metals, by using high heat to melt and fuse the parts. Two pieces of metal were welded during the measurement. Note that in the middle of sanding and the whole process of welding, the local exhaust ventilation (LEV) was on so that emission was quickly reduced to protect the operators. The 
Table 1. Detailed information on four different printing scenarios.

\begin{tabular}{|c|c|c|c|c|c|c|}
\hline & & $\begin{array}{l}\text { Duration } \\
(\mathrm{min})\end{array}$ & $\begin{array}{l}\text { Toner } \\
\text { coverage }\end{array}$ & $\begin{array}{l}\text { Highest GSA concentration } \\
\left(\mathrm{WS} ; \mu \mathrm{m}^{2} \mathrm{~cm}^{-3} \text { ) }\right.\end{array}$ & GMD & $\sigma_{\mathrm{g}}$ \\
\hline Black plain texts & $\mathrm{A}$ & 3.5 & $\sim 5 \%$ & $58.9 \pm 3.6$ & $28.1 \pm 0.7$ & $1.7 \pm 0.0$ \\
\hline Texts and pictures in color & B & 1.8 & $\sim 10 \%$ & $112.3 \pm 14.9$ & $31.8 \pm 3.5$ & $1.8 \pm 0.2$ \\
\hline Pictures in color & $\mathrm{C}$ & 7.0 & $\sim 40 \%$ & $381.8 \pm 51.3$ & $41.3 \pm 7.9$ & $1.9 \pm 0.2$ \\
\hline Pictures in red & $\mathrm{D}$ & 5.0 & $\sim 20 \%$ & $118.5 \pm 26.2$ & $38.8 \pm 5.6$ & $1.9 \pm 0.1$ \\
\hline
\end{tabular}

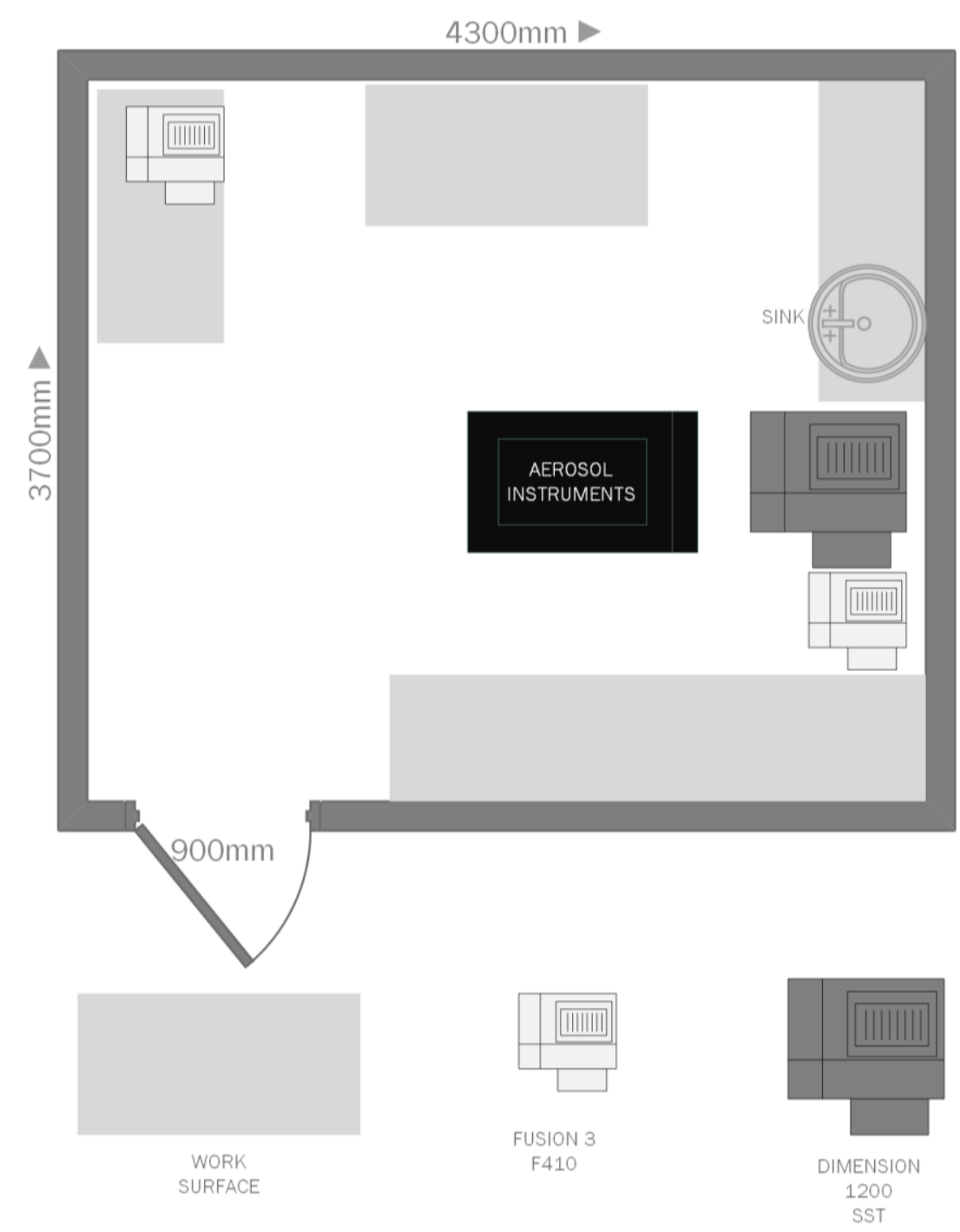

Fig. 3. Room layout for the measurement.

general duct velocity recommended in Local Exhaust Ventilation (LEV) Guidance from the Health and Safety Authority is between 5 and $25 \mathrm{~m} \mathrm{~s}^{-1}$.

\section{Ambient Environment}

This sampling took place on Thursday, March $16^{\text {th }}, 2017$, from 10:00 to 16:00. The university was on holiday and the campus was rather empty, so there were no random pollution events nearby to interfere with our sampling. The aerosol instruments were located in a room on the third floor of a building. The sampling port extended out of the window to measure the outdoor concentration.

\section{RESULTS AND DISCUSSION}

Following the order in Section 2, this section shows the results of the GSA concentration for each event, where data from both WS and SMPS were included and compared. The overall linear comparison of the GSA concentrations between SMPS and WS is presented in Fig. 5, where the overall Pearson correlation coefficient is 0.85 and the specific coefficient for each event will be introduced in each subsection. Many other figures (Figs. 6(a), 7(a), 7(b), 8, and 9) are displayed in a concentration-time manner, where the y-axis corresponding to the concentration is a logarithmic scale. Error bars (standard 


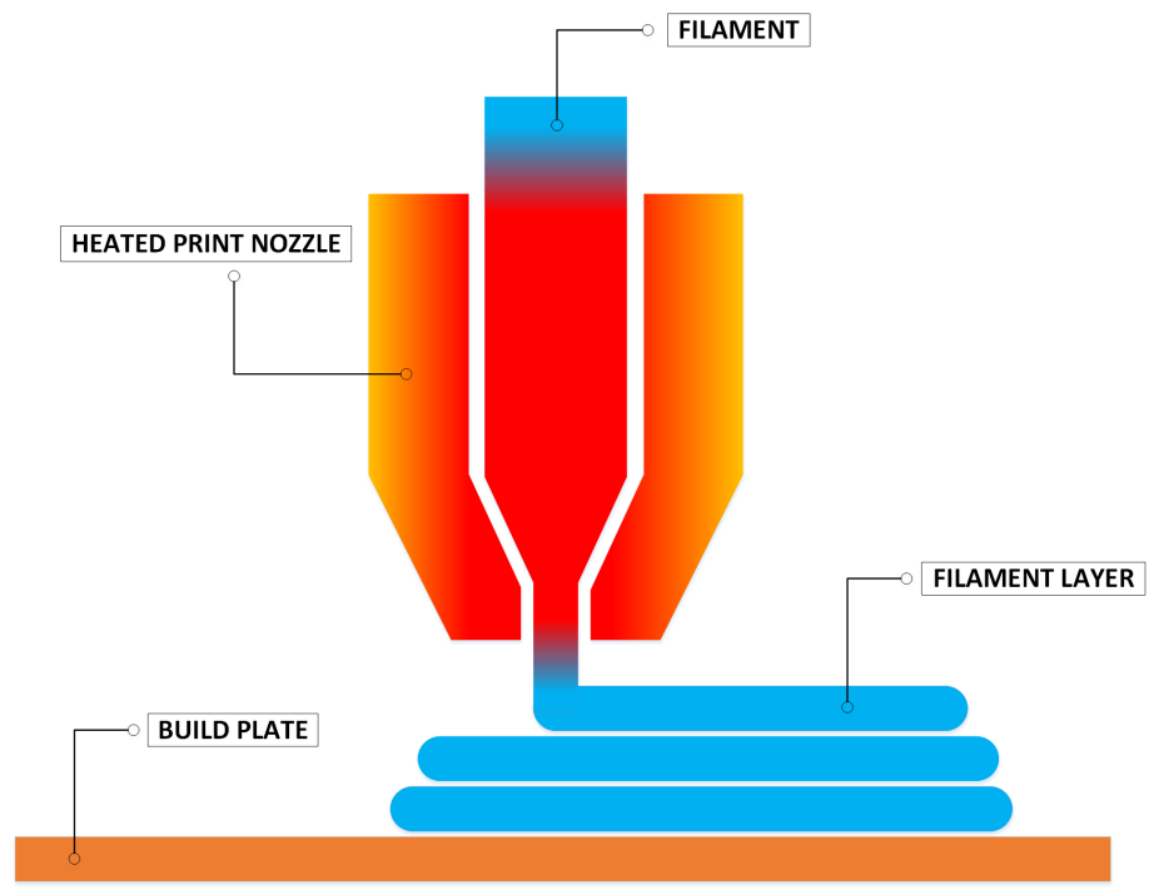

Fig. 4. The working principle of FDM 3D printer.

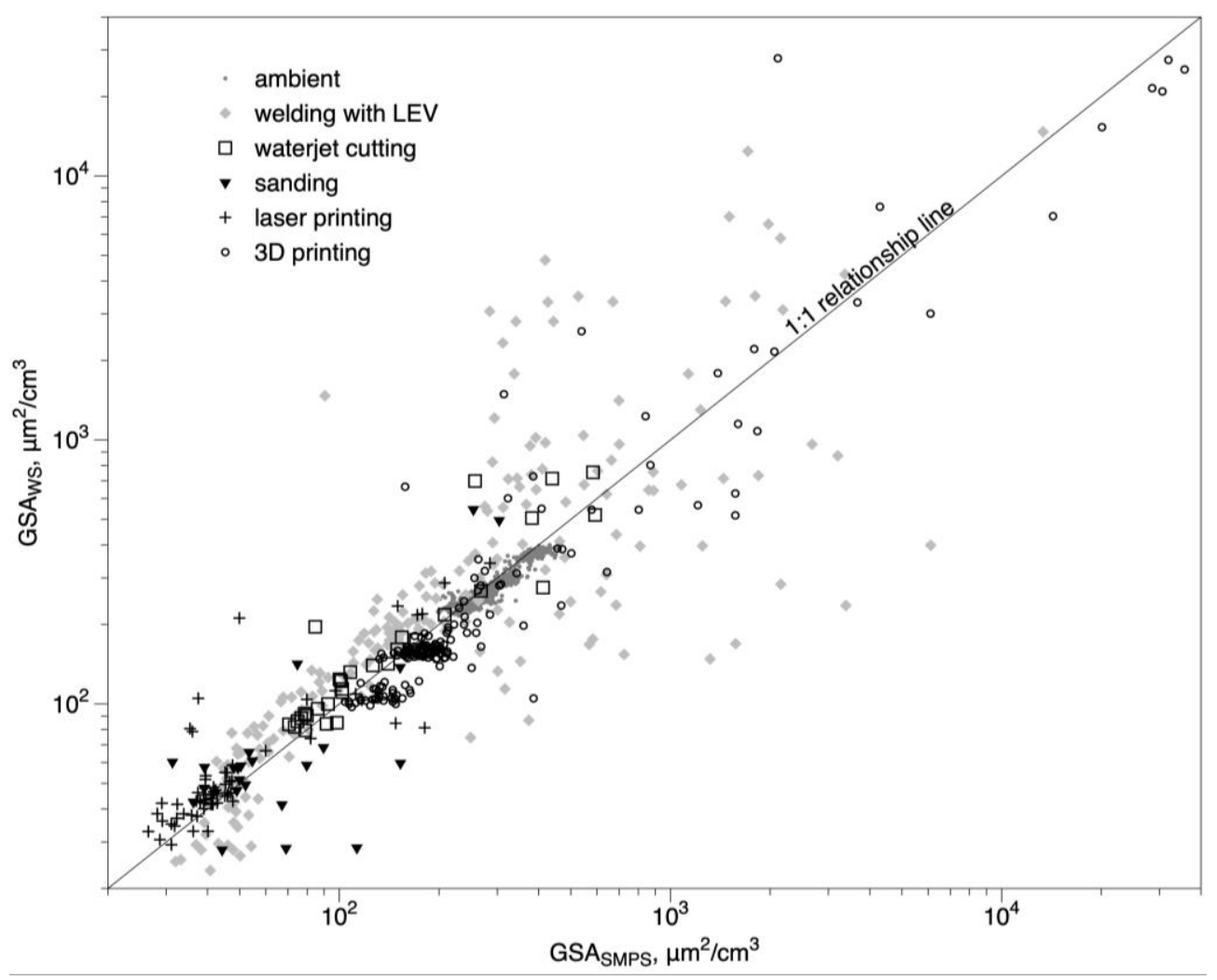

Fig. 5. The overall linear comparison of the GSA concentrations between SMSP and WS.

deviation defined in Section 2) for the data in $1 \mathrm{~min}$ are shown in gray for the WS measurements, while SMPS obtained 1 data point per min and had no error bars. In general, the results obtained by both methods are consistent in the trend as well as the GSA concentrations, whether at high concentrations in emission episodes or low concentrations for the background in the range of 30 to $4 \times 10^{4} \mu \mathrm{m}^{2} \mathrm{~cm}^{-3}$. Note that when the concentration changed rapidly relative to the sampling time of WS (16 s), e.g., in welding, several large uncertainties can be found in nearly all the figures except the 
outdoor sampling; the situation of SMPS is even worse because of its much longer sampling time (60 s). In those cases, the scan from SMPS may not accurately represent the aerosol at the time.

\section{Laser Printing}

The measurement of laser printing in the student computer lab lasted about $1 \mathrm{~h}$. The PN and GSA concentrations of printing of black plain texts, texts and pictures in color, pictures in color, and pictures in red are shown in Fig. 6(a) and their whole print processes from beginning to end are highlighted in shades as $A, B, C$, and $D$, respectively. The printing detail was summarized in Table 1 including the event duration, toner coverage, peak concentration, geometric mean diameter (GMD), and geometric standard deviation of the distribution $\left(\sigma_{\mathrm{g}}\right)$. Note that the GMD is equal to the count median diameter (CMD) in lognormal distributions (Hinds, 1999). Therefore, the CMD reported in other studies can be directly compared with our results.

The background GSA concentration was between 30 and $50 \mu \mathrm{m}^{2} \mathrm{~cm}^{-3}$; the concentration peaks for all the print jobs were between 50 and $400 \mu \mathrm{m}^{2} \mathrm{~cm}^{-3}$. Note that the background

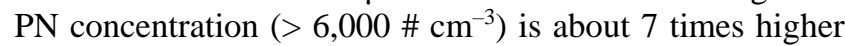
than that of the clean lab mentioned in Cao and Pui (2018), although the GSA concentrations in both measurements were close at around $40 \mu \mathrm{m}^{2} \mathrm{~cm}^{-3}$. We observed huge amounts of nanoparticles at $30 \mathrm{~nm}$ in the background (the background in Fig. 6(b)), which contribute a lot to the PN but little to the GSA concentration. In the linear comparison of the GSA concentrations between SMPS and WS (+ in Fig. 5), there was a significant positive correlation with a Pearson correlation coefficient of 0.87 even when the concentrations varied with a span of an order of magnitude.

Many other studies have also monitored the PN and GSA concentrations for laser printing (He et al., 2007; Schripp et al., 2008; Morawska et al., 2009; He et al., 2010; McGarry

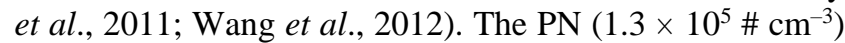
and GSA concentrations $\left(6,500 \mu \mathrm{m}^{2} \mathrm{~cm}^{-3}\right)$ shown in Fig. 1 in Mokhtar et al. (2013) are more than one magnitude higher than the highest concentration in $\mathrm{C}$, which is $1.3 \times 10^{4} \mathrm{\#} \mathrm{cm}^{-3}$ for the PN concentration and $382 \mu \mathrm{m}^{2} \mathrm{~cm}^{-3}$ for the GSA concentration. It is reasonable that the concentration in Mokhtar et al. (2013) is much higher than ours since their measurements were performed in a $1-\mathrm{m}^{3}$ environmental chamber, where concentrations can easily accumulate, while our field measurements were conducted in the open space, where the emission was quickly diluted by the background. McGarry et al. (2011) measured the particle emission of 107 laser printers in the open-plan offices. The median of peak concentration for all printing events for a high emitter, which is $2.2 \times 10^{4} \mathrm{\#} \mathrm{cm}^{-3}$ (Fig. 2 in McGarry et al., 2011), was comparable to the PN concentration in C. In addition, Morawska et al. (2009) reported an average CMD of $63.5 \mathrm{~nm}$ (during the first $2 \mathrm{~min}$ of printing) and $28.5 \mathrm{~nm}$ (during the middle 2 min of printing) for the submicrometer emission of Printer $\mathrm{H}$ with various toner coverage of $0 \%, 5 \%$, and $50 \%$. The GMD (= CMD) in our measurement was between 28.1 and $38.8 \mathrm{~nm}$, which is in the middle of the results in Morawska et al. (2009).
Sort by PN concentration from low to high, black plain texts (A), texts and pictures in color (B), pictures in red (D), and pictures in multi-color $(\mathrm{C})$ is the order, which is the same as the order of toner coverage, i.e., $5 \%, 10 \%, 20 \%$, and $40 \%$, respectively. He et al. (2007) and Wang et al. (2012) indicated that the particle emission positively correlates with toner coverage, while, in contrast, Schripp et al. (2008) and Morawska et al. (2009) found little effect of toner coverage on the particle emission. Note that although SMPS shows that both the highest PN and GSA concentrations from D are 1.5 times higher than B, WS shows no significant difference. This disagreement between SMPS and WS is attributed to the overestimation from the SMPS scan due to the rapid change of aerosol concentration, which was observed by WS.

The same thing about $\mathrm{C}$ and $\mathrm{D}$ is that they all printed only pictures. However, the GSA concentration from $\mathrm{C}$, which is the highest among all prints, is about 3 times higher than D. Except the higher toner coverage (40\%), the multi-color printing could be another reason for the higher concentration compared with monochrome printing in D. Our results are consistent with previous studies (Schripp et al., 2008; He et al., 2010), where He et al. (2010) showed that multi-color printing leads to 2-3 times more PN concentration than monochrome printing for the same printer, although the reason remains unclear. Many other parameters are also affecting the PN concentration including the printing speed, toner temperature, and toner cartridge condition (Pirela et al., 2017). However, other than monochrome and color printing, the parameters affecting the PN concentration are beyond the scope of this study and unable to be identified from this data set since the field measurements were not strictly controlled for comparison.

\section{D Printing}

The 3-h time series of the GSA and PN concentrations were shown in Figs. 7(a) and 7(b), respectively, where the solid line represents WS and the dotted line represents SMPS. The timeline was also indicated in the figure. The printer was turned on at Min 26 and started warming up with the internal ventilation on. The $1^{\text {st }}$ and the $2^{\text {nd }}$ prints started at Min 48 and 128, respectively. Each print took $70 \mathrm{~min}$. The sampling tube was outside the enclosure from the beginning until Min 128 and moved into the enclosure.

It is apparent that the concentration inside the enclosure was much higher than that outside the enclosure, e.g., the GSA concentration inside at the very beginning of the $2^{\text {nd }}$ print was about two orders of magnitude higher than that outside. An obvious PN peak (Min 30-45; Fig. 7(b)) was detected right after the printer was turned on and the concentration stayed elevated for at least $10 \mathrm{~min}$. We feel that the emission was not leaking from the enclosure since no obvious peak was found during the $1^{\text {st }}$ print, whose PN concentration in the chamber should be as high as $1 \times$ $10^{6}{\mathrm{\#} \mathrm{cm}^{-3}}^{-}$, similar to the $2^{\text {nd }}$ print. Thus, the peak right after the boot of the 3D printer was most likely due to other random events happened in the room.

For the $2^{\text {nd }}$ print, the GSA concentration rose quickly to 5 $\times 10^{4} \mu \mathrm{m}^{2} \mathrm{~cm}^{-3}$. The reason for the high emission is that preheating the materials generates large amounts of particles 
(a)

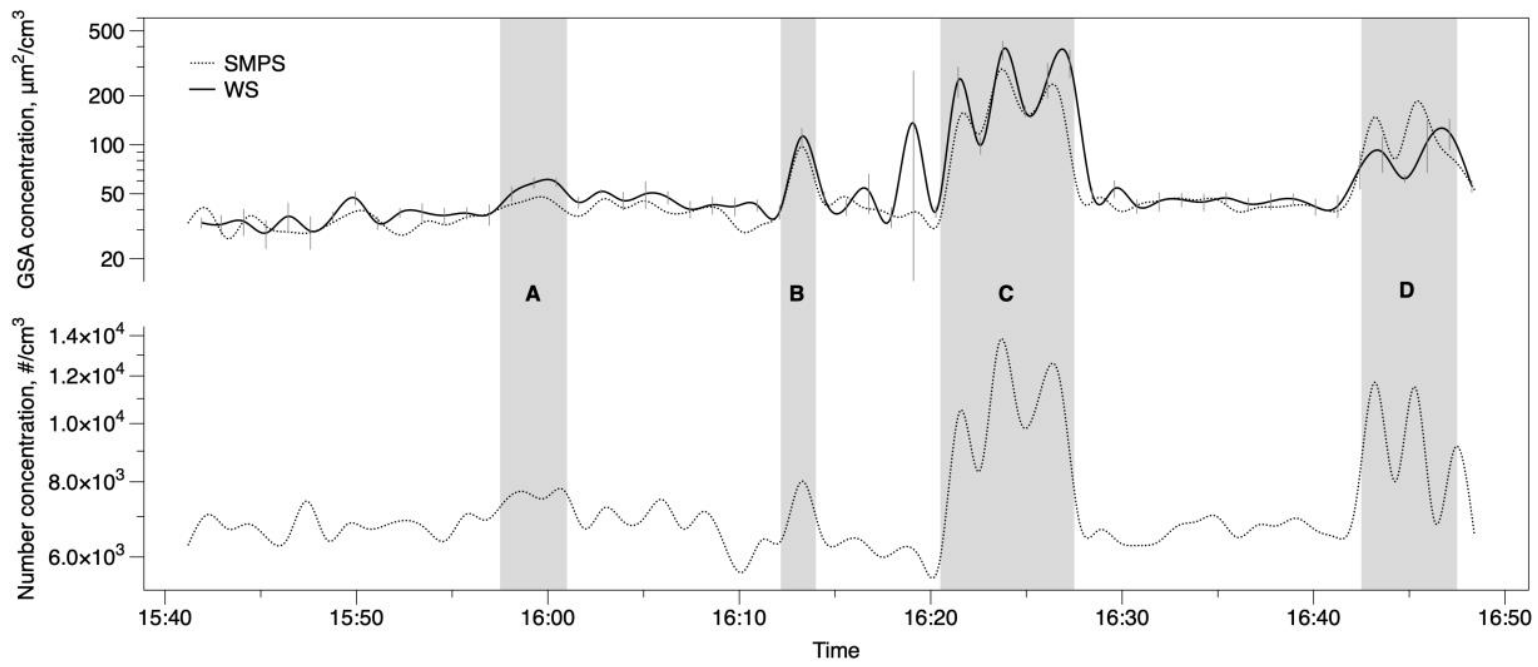

(b)
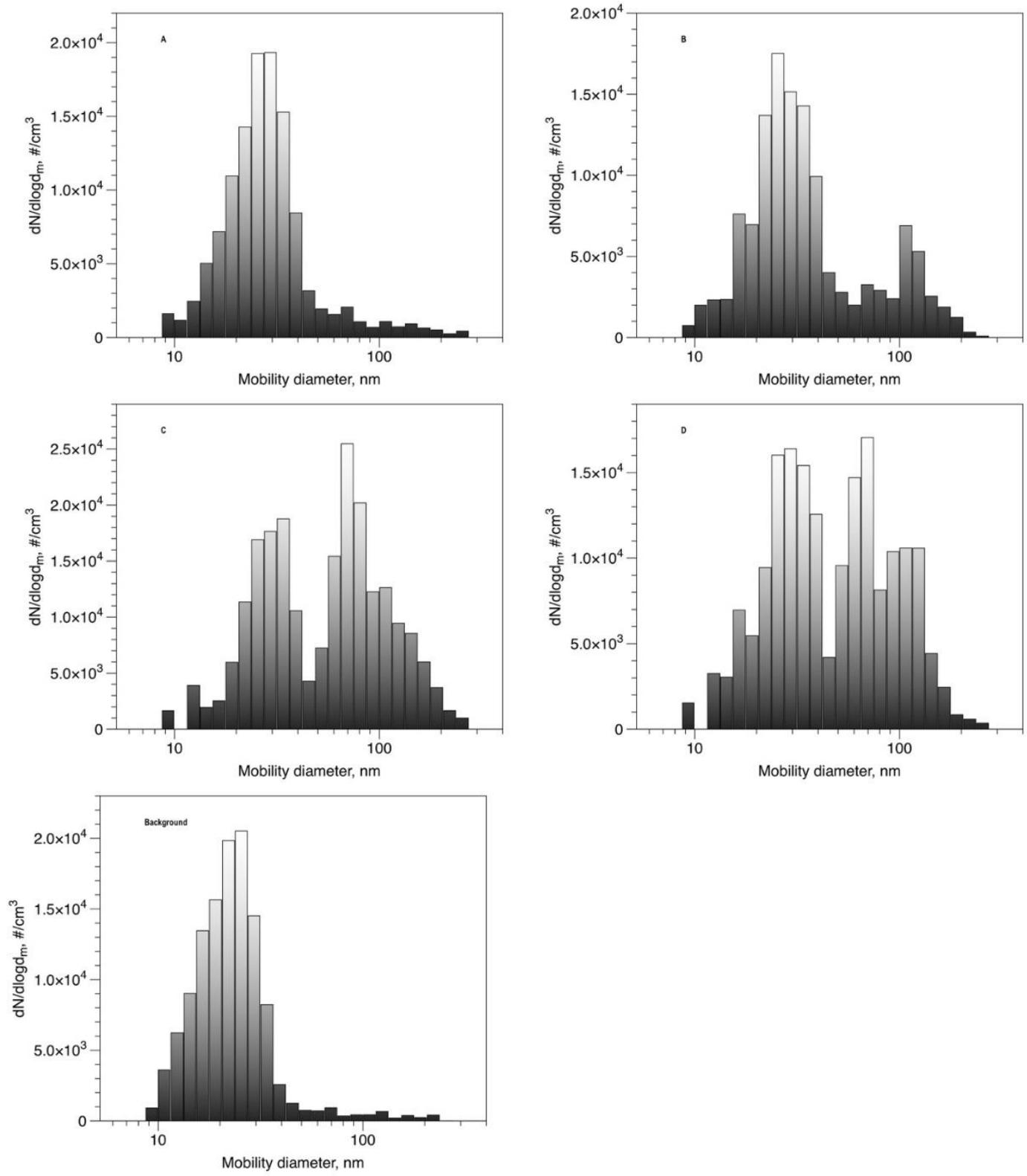

Fig. 6. (a) Time series of the GSA concentration and (b) exemplary aerosol size distributions for the prints of A, B, C, D, and the background. 
(a)

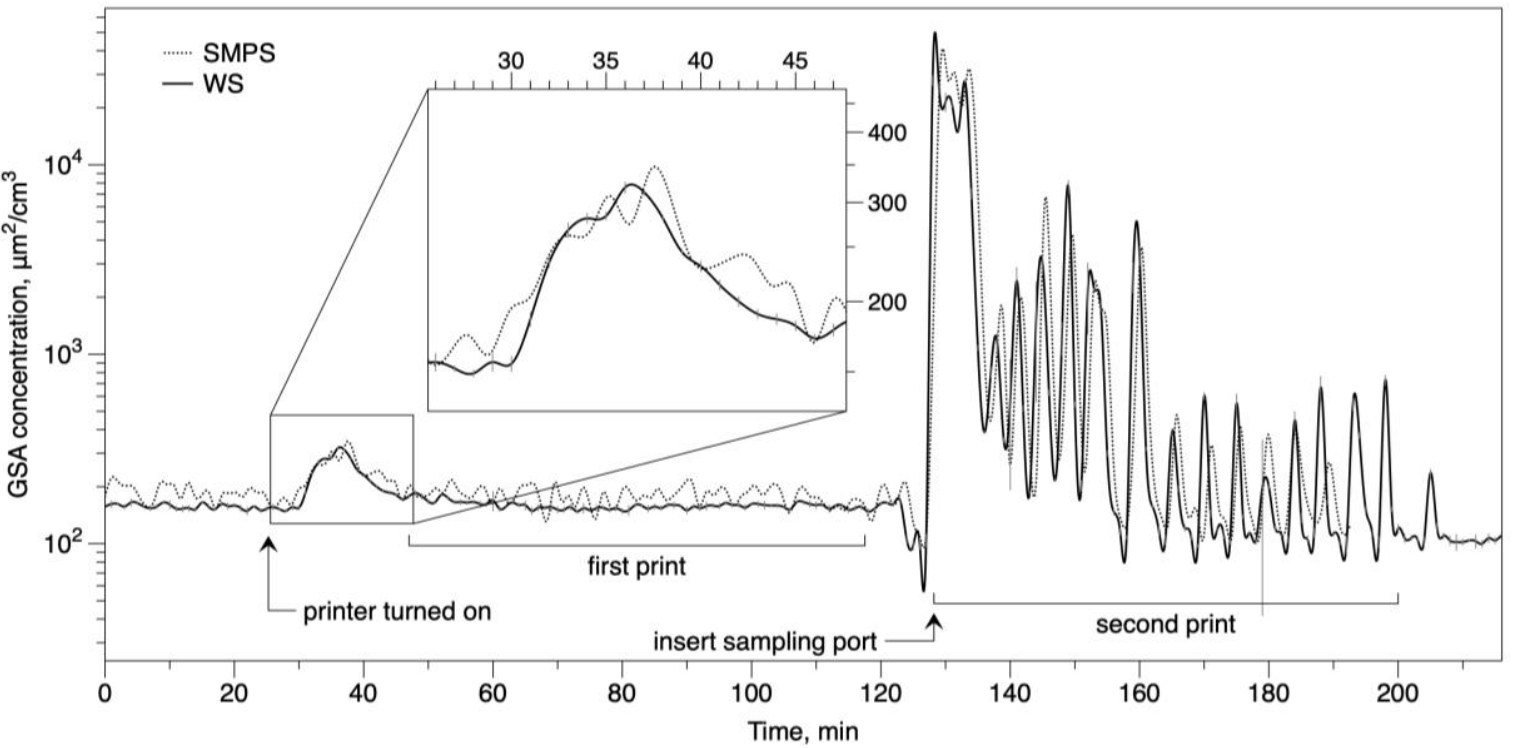

(b)

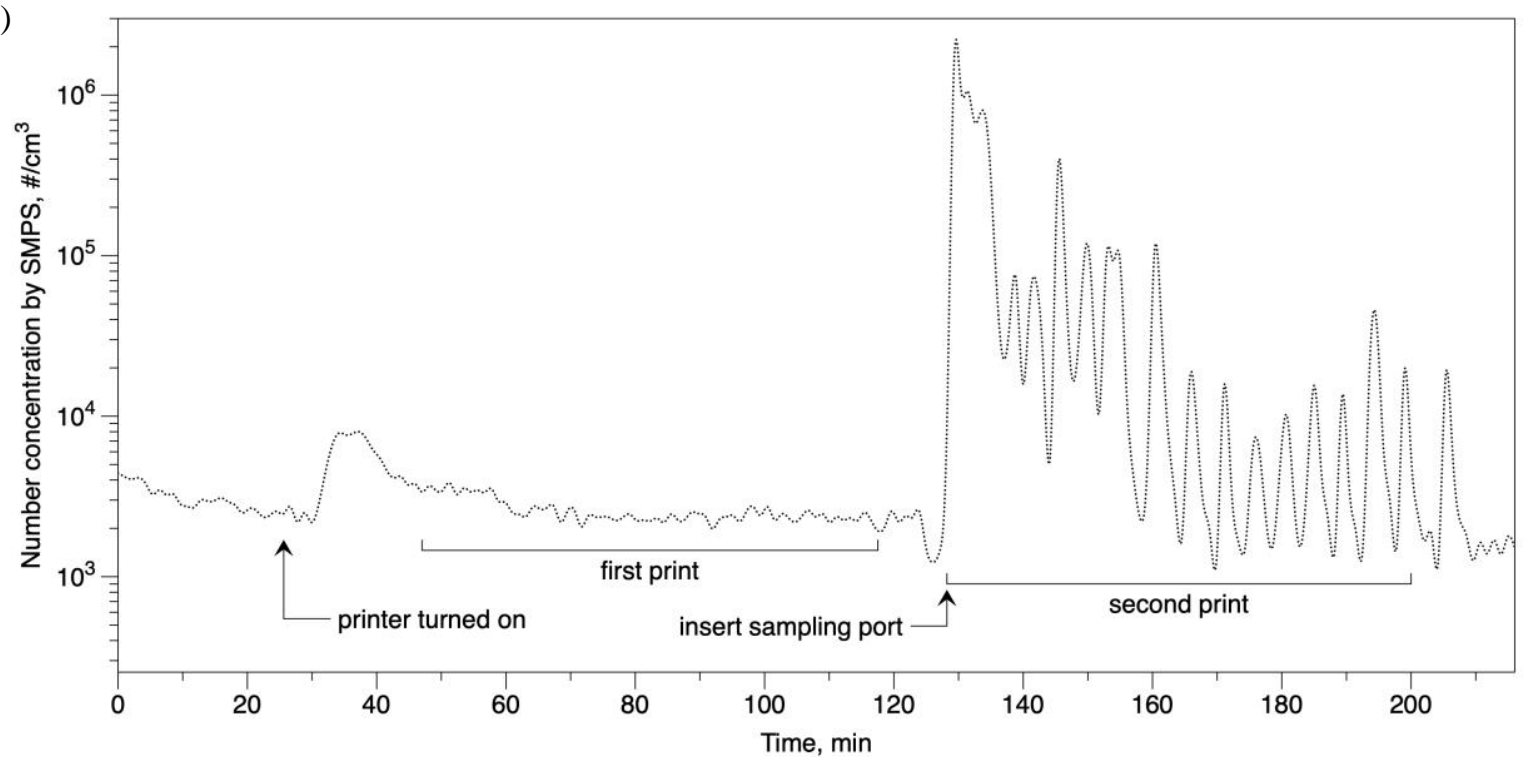

(c)

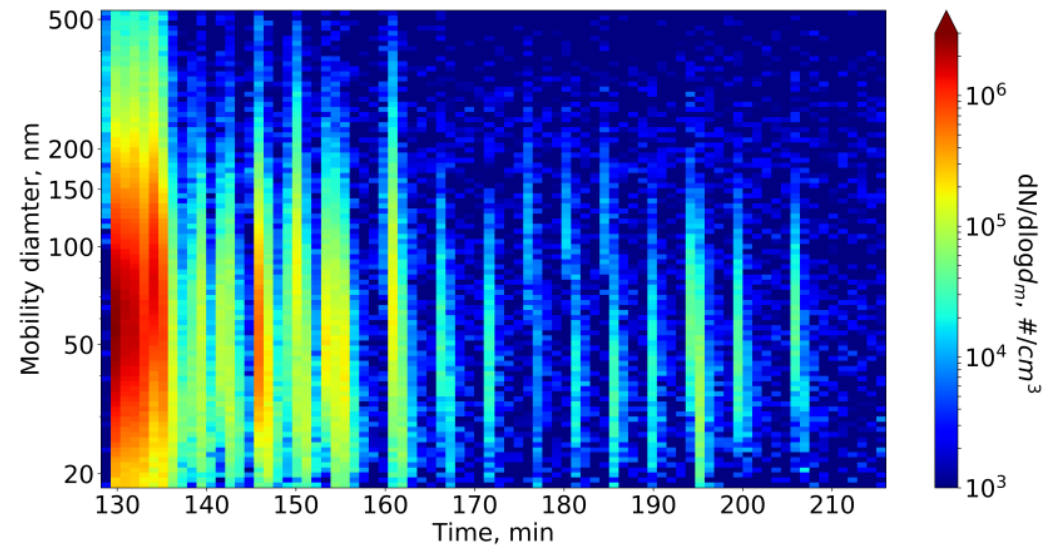

Fig. 7. (a) GSA concentration over time, (b) PN concentration over time, and (c) aerosol size distribution over time.

(Azimi et al., 2016; Zhang et al., 2018). What makes the measurements challenging is the wave pattern with 16 waves in the 70-min printing (Fig. 7). In addition, the peak is more than an order of magnitude higher than the valley in several waves. The pattern was most likely due to the combination of the constant particle generation and the efficient air filtration of 4 fan filters. Fig. 7(c) shows the PN concentrationdiameter distribution over time from the start of the $2^{\text {nd }}$ print 
to the end of the sampling. In spite of the wavy concentration, both methods agreed extremely well with each other during the measurement with a Pearson correlation coefficient of 0.88 from the linear comparison in Fig. 5 .

The peak PN concentrations of the waves for printing with ABS filaments were between $1 \times 10^{4}$ to $1 \times 10^{6} \# \mathrm{~cm}^{-3}$. This particle emission range was consistent with other studies that have also measured the ABS emission of 3D printing (Stephen et al., 2013; Azimi et al., 2016; Zhang et al., 2017; Zhang et al., 2018). Stephens et al. (2013) reported on measurements of 3D printer emission inside a commercial office space, where the highest concentration is $1.5 \times$ $10^{5} \mathrm{\#} \mathrm{cm}^{-3}$ when 2 printers with PLA and 3 printers with ABS were on at the same time. Azimi et al. (2016) measured the emission from ABS printing in a $3.6-\mathrm{m}^{3}$ chamber with a mixing fan with the PN concentration from $4 \times 10^{5}$ to $1 \times$ $10^{6} \# \mathrm{~cm}^{-3}$ for the main printing. Zhang et al. (2017) monitored 6 printers with various materials in a $1-\mathrm{m}^{3}$ environmental chamber with 1 air change per $h$. The average maximum concentration for ABS printing is between $1 \times 10^{5}$ and $1 \times 10^{6} \mathrm{\#} \mathrm{cm}^{-3}$. The geometric mean diameter and the geometric standard deviation of the distribution $\left(\sigma_{\mathrm{g}}\right)$ in Fig. 7(c) were $67.0 \pm 25.4$ and $2.0 \pm 0.3$, respectively. The CMD (= GMD) for the ABS measurement in Kim et al. (2015) is $32.6 \pm 1.1$ during printing and $50.5 \pm 1.1$ after the operation. The peak diameter was between 36.5 and $48.7 \mathrm{~nm}$ in Stephens et al. (2013). The average GMD is around 65 $\mathrm{nm}$ for the ABS printing in Zhang et al. (2017). Note that the GMD for 3D printing was about twice that from laser printing (28.1-38.8 nm) in our measurements.

The three factors including the internal air circulation, the filtration system, and the well-sealed printing chamber make our measurement different from other measurements of 3D printer emission. We observed a drastic concentration drop within a few minutes of printing stop, while it took more than half an hour for the concentration to drop to the background level in the above studies. This indicates that an internal filtration system with an enclosure (not necessarily airtight) could be one of the solutions to the emission problem of the 3D printers. In fact, the model results in Zhang et al. (2018) suggested removing particles near the extruder nozzle to eliminate 3D printing emission.

\section{Machining}

The emissions of multiple events in the machine shop were measured and the 4.5-h time series of the GSA concentrations were shown in Fig. 8. The particle concentration of the waterjet cutting was as low as the background during the warming up; the main cutting lasted $5 \mathrm{~min}$ and the concentration stayed elevated at $700 \mu \mathrm{m}^{2} \mathrm{~cm}^{-3}$. Although the background concentration for the sanding was slightly lower than that of waterjet cutting, once the grinding began, the concentration rose to the level of waterjet cutting. In the middle of the grinding process, the local exhaust ventilation was turned on and the emission was immediately eliminated. Therefore, the LEV is a very effective option to protect the workers against the particle emission.

The emission from the welding process was extremely high compared with other machining processes. For example, the highest concentration from welding (even with LEV) was one magnitude higher than those from the waterjet cutting and sanding and slightly lower than the first burst in $3 \mathrm{D}$ printing (Section 3.2). Thus, the LEV must be turned on all the time to protect the worker against the severe emission. However, the efficient particle removal of the LEV and the burst of particle generation led to the drastic change in the emission in a wide concentration range in seconds, namely, very transient and unstable that made the measurement extremely difficult. As a result, welding had much larger errors for the WS method compared with waterjet cutting and sanding; SMPS frequently obtained inaccurate scans that may not represent the true aerosol distribution.

In general, the WS and SMPS methods agreed well with each other with Pearson correlation coefficients of 0.87 , 0.67 , and 0.89 for waterjet cutting, welding, and sanding, respectively. Although the emission from welding was fairly transient, the concentrations and trends from both methods were still comparable.

\section{Ambient Environment}

The outdoor GSA concentration was monitored for about $6 \mathrm{~h}$ from 10:00 to 16:00 (Fig. 9). The concentration was

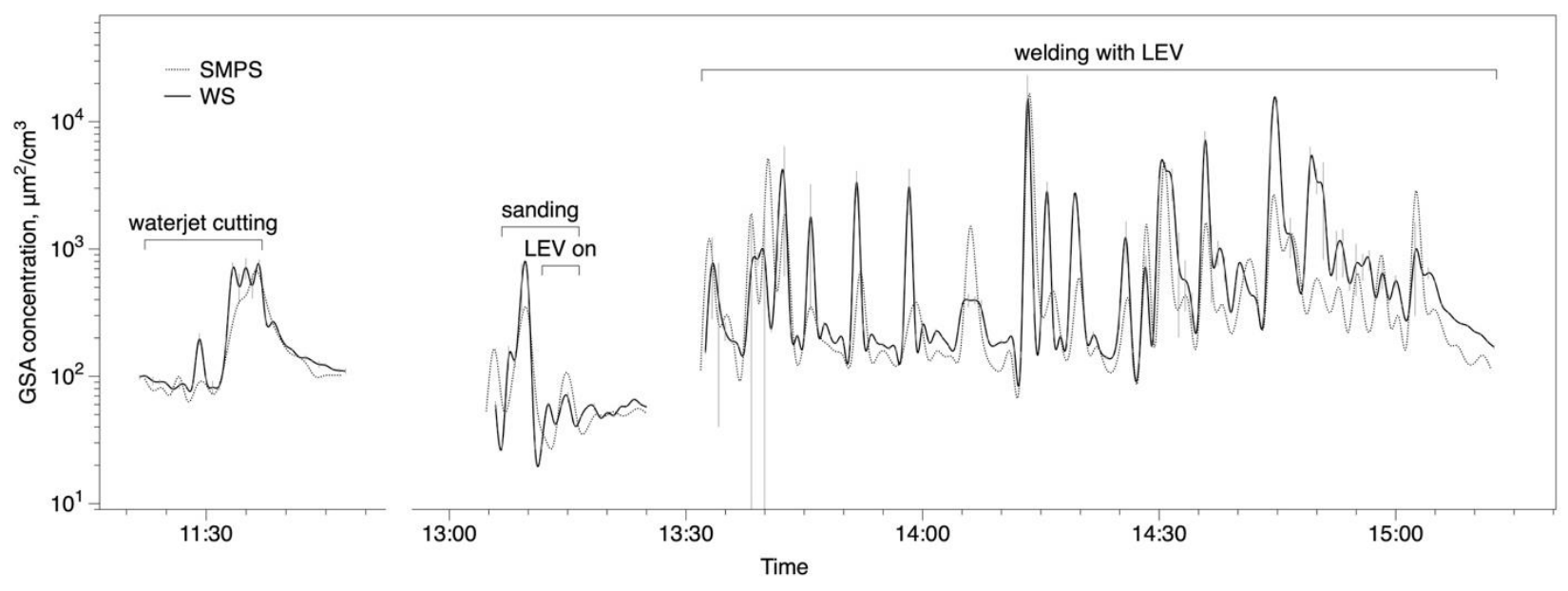

Fig. 8. Time series of GSA concentrations in the machine shop by SMPS and WS. 
(a)

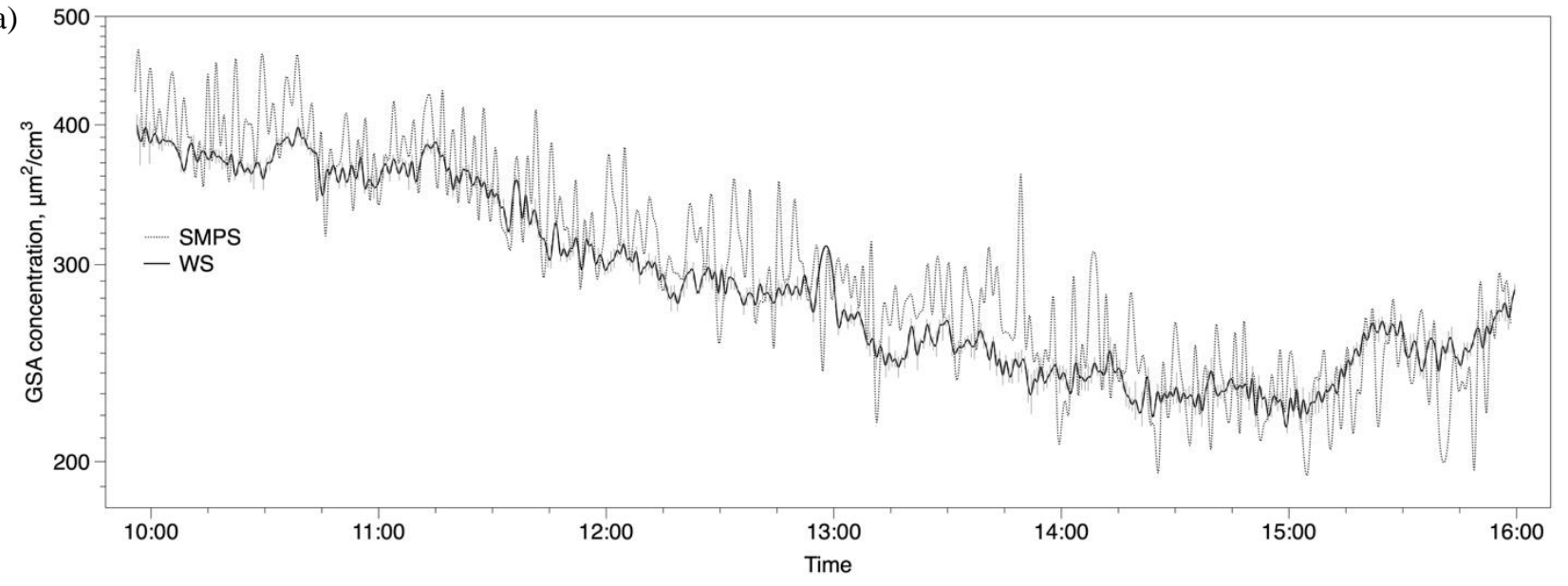

(b)

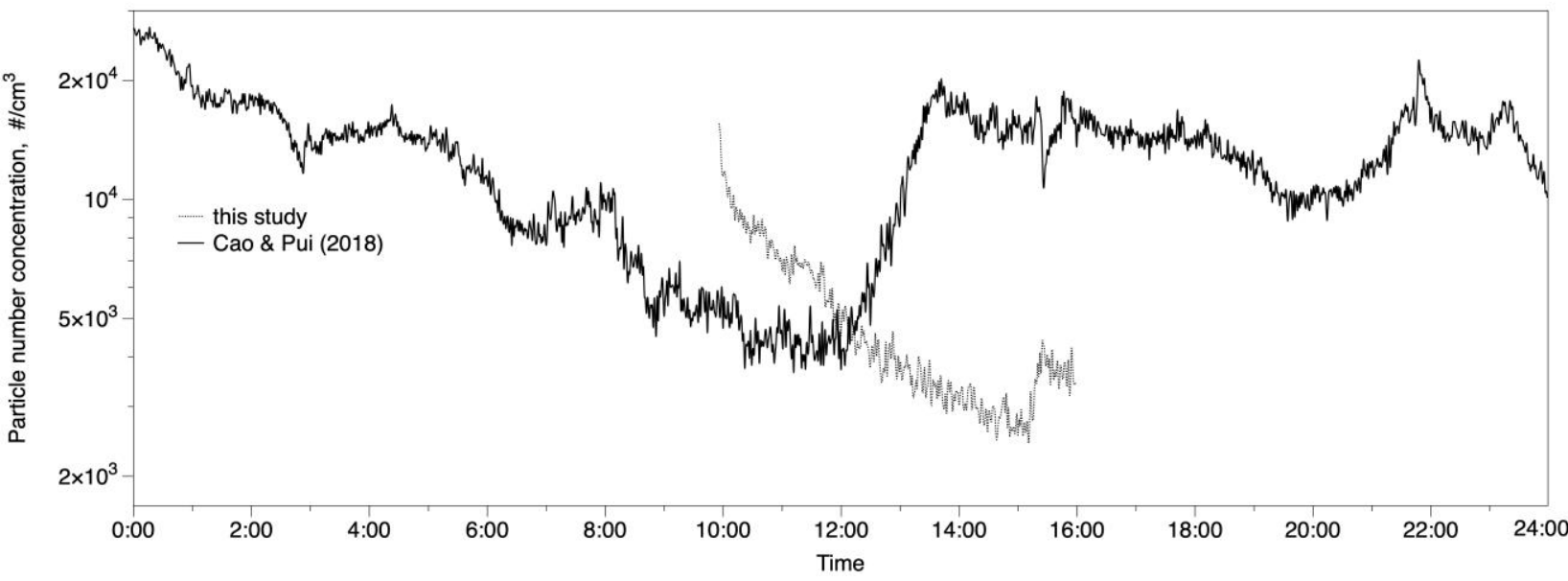

Fig. 9. (a) Time series of GSA concentrations for the outdoor environment by SMPS and WS. b) PN concentrations of the outdoor sampling in this study, and Cao and Pui (2018). The data for Cao and Pui (2018) was taken on Saturday, May 13 ${ }^{\text {th }}$, 2017.

between 200 and $500 \mu \mathrm{m}^{2} \mathrm{~cm}^{-3}$, which is consistent with the 5-d outdoor GSA measurement in Cao and Pui (2018). Although SMPS shows more fluctuation than WS that was already explained in Section 4.4 in Cao and Pui (2018), the results from both methods agreed with each other for the duration with a Pearson correlation coefficient of 0.94 . The PN concentration is shown in Fig. 9(b) along with the 24-h data from Cao and Pui (2018).

The range of PN concentration in this study is between 2,440 and 15,500 \# $\mathrm{cm}^{-3}$, which is consistent with the results in Cao and Pui (2018), between 3,660 and 27,200 $\# \mathrm{~cm}^{-3}$.

\section{CONCLUSION}

This study investigated the accuracy of the weighted-sum approach, which was developed to measure the aerosol geometric surface area concentration in real time (Cao and Pui, 2018), for various scenarios. To that end, we applied the WS method and concurrently used an SMPS to measure the particle GSA concentrations emitted during laser printing, $3 \mathrm{D}$ printing, and machining, as well as those present in the ambient environment. The two methods agreed well with each other across a wide range of concentrations, with an overall Pearson correlation coefficient of 0.85 , despite large uncertainties for the extremely transient aerosol produced by welding. Fortunately, Su et al. (2019a) demonstrated a solution to this obstacle by setting a maximum time resolution of $1 \mathrm{~s}$. Using the GSA concentrations measured in this study as a reference, affected personnel can protect themselves accordingly. Additional systematic measurements can be conducted in future research to assess the relationship between GSA concentrations and adverse health effects.

\section{ACKNOWLEDGMENTS}

This work was supported by National Science Foundation (NSF) Grant 1236107, "GOALI: Unipolar Diffusion Charging of Spherical and Agglomerated Nanoparticles and its Application toward Surface-area Measurement." The authors thank the support of members of the Center for Filtration Research: 3M Corporation; A.O. Smith Company; Applied Materials, Inc.; BASF Corporation; Boeing Company; Corning Co.; China Yancheng Environmental Protection Science and Technology City; Cummins Filtration Inc.; Donaldson Company, Inc.; Entegris, Inc.; Ford Motor Company; Guangxi Wat Yuan Filtration System Co., Ltd.; LG Electronics 
Co.; MSP Corporation; Samsung Electronics Co., Ltd.; Xinxiang Shengda Filtration Technology Co., Ltd.; TSI Inc.; W. L. Gore and Associates, Inc.; Shigematsu Works Co., Ltd.; and the affiliate member National Institute for Occupational Safety and Health (NIOSH). The authors also wish to acknowledge the College of Science and Engineering machine shop, and The Clifford I. and Nancy C. Anderson Student Innovation Labs in the University of Minnesota for the assistance and cooperation for the field measurements.

\section{REFERENCE}

Azimi, P., Zhao, D., Pouzet, C., Crain, N.E. and Stephens, B. (2016). Emissions of ultrafine particles and volatile organic compounds from commercially available desktop three-dimensional printers with multiple filaments. Environ. Sci. Technol. 50: 1260-1268. https://doi.org/10. 1021/acs.est.5b04983

Baldauf, R.W., Devlin, R.B., Gehr, P., Giannelli, R., Hassett-Sipple, B., Jung, H. and Walker, K. (2016). Ultrafine particle metrics and research considerations: review of the 2015 UFP workshop. Int. J. Environ. Res. Public Health 13: 1054. https://doi.org/10.3390/ijerph131 11054

Bau, S., Witschger, O., Gensdarmes, F., Rastoix, O. and Thomas, D. (2010). A TEM-based method as an alternative to the BET method for measuring off-line the specific surface area of nanoaerosols. Powder Technol. 200: 190 201. https://doi.org/10.1016/j.powtec.2010.02.023

Bau, S., Witschger, O., Gensdarmes, F. and Thomas, D. (2011). Response of three instruments devoted to surfacearea for monodisperse and polydisperse aerosols in molecular and transition regimes. J. Phys. Conf. Ser. 304: 012015. https://doi.org/10.1088/1742-6596/304/1/012015

Bourrous, S., Ribeyre, Q., Lintis, L., Yon, J., Bau, S., Thomas, D. and Ouf, F.X. (2018). A semi-automatic analysis tool for the determination of primary particle size, overlap coefficient and specific surface area of nanoparticles aggregates. J. Aerosol Sci. 126: 122-132. https://doi.org/10.1016/j.jaerosci.2018.09.001

Brunauer, S., Emmett, P.H. and Teller, E. (1938). Adsorption of gases in multimolecular layers. J. Am. Chem. Soc. 60: 309-319. https://doi.org/10.1021/ja01269 a023

Cao, L.N.Y., Wang, J., Fissan, H., Pratsinis, S.E., Eggersdorfer, M.L. and Pui, D.Y.H. (2015). The capacitance and charge of agglomerated nanoparticles during sintering. J. Aerosol Sci. 83: 1-11. https://doi.org/10.1016/j.jaerosci.2015.01.002

Cao, L.N.Y., Chen, S.C., Fissan, H., Asbach, C. and Pui, D. Y.H. (2017). Development of a geometric surface area monitor (GSAM) for aerosol nanoparticles. J. Aerosol Sci. 114: 118-129. https://doi.org/10.1016/j.jaerosci.2017. 09.013

Cao, L.N.Y. and Pui, D.Y.H. (2018). A novel weighted sum method to measure particle geometric surface area in realtime. J. Aerosol Sci. 117: 11-23. https://doi.org/10.1016/ j.jaerosci.2017.12.007

Fierz, M., Burtscher, H., Steigmeier, P. and Kasper, M. (2008). Field measurement of particle size and number concentration with the diffusion size classifier (Disc). SAE Technical Paper 2008-01-1179. https://doi.org/10.42 71/2008-01-1179

Fierz, M., Houle, C., Steigmeier, P. and Burtscher, H. (2011). Design, calibration, and field performance of a miniature diffusion size classifier. Aerosol Sci. Technol. 45: 1-10. https://doi.org/10.1080/02786826.2010.516283

Fierz, M., Meier, D., Steigmeier, P. and Burtscher, H. (2013). Aerosol measurement by induced currents. Aerosol Sci. Technol. 48: 350-357. https://doi.org/10.1080 /02786826.2013.875981

Fissan, H., Neumann, S., Trampe, A., Pui, D.Y.H. and Shin, W.G. (2007). Rationale and principle of an instrument measuring lung deposited nanoparticle surface area. $J$. Nanopart. Res. 9: 53-59. https://doi.org/10.1007/s11051006-9156-8

Fissan, H., Asbach, C., Kaminski, H. and Kuhlbusch, T.A.J. (2012). Total surface area concentration measurements of nanoparticles in gases with an electrical sensor. Chem. Ing. Tech. 84: 365-372. https://doi.org/10.1002/cite.2011 00213

Gäggeler, H.W., Baltensperger, U., Emmenegger, M., Jost, D.T., Schmidt-Ott, A., Haller, P. and Hofmann, M. (1989). The epiphaniometer, a new device for continuous aerosol monitoring. J. Aerosol Sci. 20: 557-564. https://doi.org/10.1016/0021-8502(89)90101-8

Geiss, O., Bianchi, I. and Barrero-Moreno, J. (2016). Lungdeposited surface area concentration measurements in selected occupational and non-occupational environments. J. Aerosol Sci. 96: 24-37. https://doi.org/10.1016/j.jaerosci. 2016.02.007

Gini, M.I., Helmis, C.G. and Eleftheriadis, K. (2013). Cascade Epiphaniometer: An instrument for aerosol "Fuchs" surface area size distribution measurements. J. Aerosol Sci. 63: 87-102. https://doi.org/10.1016/j.jaerosci.2013.05.001

He, C., Morawska, L. and Taplin, L. (2007). Particle Emission Characteristics of Office Printers. Environ. Sci. Technol. 41: 6039-6045. https://doi.org/10.1021/es063049z

He, C., Morawska, L., Wang, H., Jayaratne, R., McGarry, P., Richard Johnson, G. and Ayoko, G. (2010). Quantification of the relationship between fuser roller temperature and laser printer emissions. J. Aerosol Sci. 41: 523-530. https://doi.org/10.1016/j.jaerosci.2010.02.015

Hinds, W.C. (1999). Aerosol technology: Properties, behavior, and measurement of airborne particles. WileyInterscience, New York.

Iavicoli, I., Fontana, L., Pingue, P., Todea, A.M. and Asbach, C. (2018). Assessment of occupational exposure to engineered nanomaterials in research laboratories using personal monitors. Sci. Total Environ. 627: 689-702. https://doi.org/10.1016/j.scitotenv.2018.01.260

Jung, H. and Kittelson, D.B. (2005). Characterization of Aerosol Surface Instruments in Transition Regime. Aerosol Sci. Technol. 39: 902-911. https://doi.org/10.1080/ 02786820500295701

Kim, Y., Yoon, C., Ham, S., Park, J., Kim, S., Kwon, O. and Tsai, P.J. (2015). Emissions of nanoparticles and Gaseous material from 3D printer operation. Environ. Sci. Technol. 49: 12044-12053. https://doi.org/10.1021/acs.est.5b02805 
$\mathrm{Ku}$, B.K. (2010). Determination of the ratio of diffusion charging-based surface area to geometric surface area for spherical particles in the size range of $100-900 \mathrm{~nm} . J$. Aerosol Sci. 41: 835-847. https://doi.org/10.1016/j.jaerosci. 2010.05.008

Kuuluvainen, H., Poikkimäki, M., Järvinen, A., Kuula, J., Irjala, M., Dal Maso, M. and Rönkkö, T. (2018). Vertical profiles of lung deposited surface area concentration of particulate matter measured with a drone in a street canyon. Environ. Pollut. 241: 96-105. https://doi.org/10.1016/j.en vpol.2018.04.100

Lebouf, R.F., Stefaniak, A.B., Chen, B.T., Frazer, D.G. and Virji, M.A. (2011). Measurement of airborne nanoparticle surface area using a filter-based gas adsorption method for inhalation toxicology experiments. Nanotoxicology 5: 687-699. https://doi.org/10.3109/17435390.2010.546951

Li, L., Chen, D.R. and Tsai, P.J. (2009). Use of an electrical aerosol detector (EAD) for nanoparticle size distribution measurement. J. Nanopart. Res. 11: 111-120. https://doi. org/10.1007/s11051-008-9418-8

Marra, J., Voetz, M. and Kiesling, H.J. (2010). Monitor for detecting and assessing exposure to airborne nanoparticles. J. Nanopart. Res. 12: 21-37. https://doi.org/10.1007/s110 51-009-9695-x

Mokhtar, M.A., Jayaratne, R., Morawska, L., Mazaheri, M., Surawski, N. and Buonanno, G. (2013). NSAM-derived total surface area versus SMPS-derived "mobility equivalent" surface area for different environmentally relevant aerosols. J. Aerosol Sci. 66: 1-11. https://doi.org/ 10.1016/j.jaerosci.2013.08.003

Morawska, L., He, C., Johnson, G., Jayaratne, R., Salthammer, T., Wang, H. and Wensing, M. (2009). An investigation into the characteristics and formation mechanisms of particles originating from the operation of laser printers. Environ. Sci. Technol. 43: 1015-1022. https://doi.org/10. 1021/es802193n

Oberdörster, G. (2000). Pulmonary effects of inhaled ultrafine particles. Int. Arch. Occup. Environ. Health 74: 1-8. https://doi.org/10.1007/s004200000185

Pandis, S.N., Baltensperger, U., Wolfenbarger, J.K. and Seinfeld, J.H. (1991). Inversion of aerosol data from the epiphaniometer. J. Aerosol Sci. 22: 417-428. https://doi.org/ 10.1016/0021-8502(91)90002-Y

Pirela, S.V., Martin, J., Bello, D. and Demokritou, P. (2017). Nanoparticle exposures from nano-enabled toner-based printing equipment and human health: state of science and future research needs. Crit. Rev. Toxicol. 47: 678-704. https://doi.org/10.1080/10408444.2017.1318354

Ramachandran, G., Paulsen, D., Watts, W. and Kittelson, D. (2005). Mass, surface area and number metrics in diesel occupational exposure assessment. J. Environ. Monit. 7: 728-735. https://doi.org/10.1039/B503854E

Schmid, O. and Stoeger, T. (2016). Surface area is the biologically most effective dose metric for acute nanoparticle toxicity in the lung. J. Aerosol Sci. 99: 133143. https://doi.org/10.1016/j.jaerosci.2015.12.006

Schripp, T., Wensing, M., Uhde, E., Salthammer, T., He, C. and Morawska, L. (2008). Evaluation of ultrafine particle emissions from laser printers using emission test chambers. Environ. Sci. Technol. 42: 4338-4343. https://doi.org/10. 1021/es702426m

Shen, S., Jaques, P.A., Zhu, Y., Geller, M.D. and Sioutas, C. (2002). Evaluation of the SMPS-APS system as a continuous monitor for measuring $\mathrm{PM}_{2.5}, \mathrm{PM}_{10}$ and coarse $\left(\mathrm{PM}_{2.5-10}\right)$ concentrations. Atmos. Environ. 36: 39393950. https://doi.org/10.1016/S1352-2310(02)00330-8

Stephens, B., Azimi, P., El Orch, Z. and Ramos, T. (2013). Ultrafine particle emissions from desktop 3D printers. Atmos. Environ. 79: 334-339. https://doi.org/10.1016/j.a tmosenv.2013.06.050

Stone, V., Johnston, H. and Clift, M.J.D. (2007). Air Pollution, ultrafine and nanoparticle toxicology: Cellular and molecular interactions. IEEE Trans. Nanobiosci. 6: 331-340. https://doi.org/10.1109/TNB.2007.909005

Su, L., Ou, Q., Cao, L.N.Y., Du, Q. and Pui, D.Y.H. (2019a). A new instrument prototype to measure the geometric surface area of nanoparticles with a time resolution of $1 \mathrm{~s}$. J. Aerosol Sci. 132: 32-43. https://doi.org/10.1016/j.jaeros ci.2019.03.007

Su, L., Ou, Q., Cao, L.N.Y., Du, Q. and Pui, D.Y.H. (2019b). Real-time measurement of nano-agglomerate and aggregate mass and surface area concentrations with a prototype instrument. Aerosol Sci. Technol. 53: 14531467. https://doi.org/10.1080/02786826.2019.1671578

Todea, A.M., Beckmann, S., Kaminski, H. and Asbach, C. (2015). Accuracy of electrical aerosol sensors measuring lung deposited surface area concentrations. J. Aerosol Sci. 89: 96-109. https://doi.org/10.1016/j.jaerosci.2015.07.003

Wang, H., He, C., Morawska, L., McGarry, P. and Johnson, G. (2012). Ozone-initiated particle formation, particle aging, and precursors in a laser printer. Environ. Sci. Technol. 46: 704-712. https://doi.org/10.1021/es203066k

Wei, J. (2007). Development of a method for measuring surface area concentration of ultrafine particles. Ph.D. Thesis, University Duisburg-Essen, Germany.

Wojtyła, S., Klama, P. and Baran, T. (2017). Is 3D printing safe? Analysis of the thermal treatment of thermoplastics: ABS, PLA, PET, and nylon. J. Occup. Environ. Hyg. 14: D80-D85. https://doi.org/10.1080/15459624.2017.1285489

Zhang, Q., Wong, J.P.S., Davis, A.Y., Black, M.S. and Weber, R.J. (2017). Characterization of particle emissions from consumer fused deposition modeling 3D printers. Aerosol Sci. Technol. 51: 1275-1286. https://doi.org/10.10 80/02786826.2017.1342029

Zhang, Q., Sharma, G., Wong, J.P.S., Davis, A.Y., Black, M.S., Biswas, P. and Weber, R.J. (2018). Investigating particle emissions and aerosol dynamics from a consumer fused deposition modeling 3D printer with a lognormal moment aerosol model. Aerosol Sci. Technol. 52: 10991111. https://doi.org/10.1080/02786826.2018.1464115

Received for review, December 6, 2019 Revised, December 6, 2019 Accepted, February 3, 2020 